\title{
Determination of Ash in GR-S Synthetic Rubbers and Latices
}

\author{
Frederic J. Linnig, Lewis T. Milliken, and Ralph I. Cohen
}

\begin{abstract}
Rapid methods are described for the determination of the ash content of GR-S synthetic rubbers and latices. Filter paper and filter pulp are used to prevent either material from overrunning the edge of the crucible when introduced into the furnace at the ashing temperature. Water is used to facilitate the burning of the carbonaceous residue obtained in ashing GR-S latex. These procedures have been put into use in the control testing of GR-S production. They are as precise as older methods of ashing and far less time-consuming. The techniques employed should be applicable to other organic materials.
\end{abstract}

\section{Introduction}

The determination of ash is an important factor in controlling the quality of GR-S synthetic rubbers and latices and in assuring the consumer that his material meets the requirements of the specification. Methods used in ashing natural rubber $[4,8,9],{ }^{1}$ natural rubber latex $[7,8,9,18]$, and other similar organic compounds $[1,2,3,5,6]$ call for distillation of the dry sample by gradually raising the temperature of the specimen from room temperature to a point somewhat below the ignition temperature of the gases formed. The carbonaceous residue is then ashed to constant weight at temperatures varying from $400^{\circ}$ to $550^{\circ} \mathrm{C}$, depending on the substance tested. This distillation procedure is too time consuming for control testing. Introduction of GR-S rubber into a muffle furnace at the final ashing temperature, as suggested by one of the plant laboratories [17], yields satisfactory results with many samples. However, when applied to certain samples of GR-S rubber, particularly those coagulated with alum, this procedure yields results that may be low by as much as 30 percent. These low results are due to loss of material that froths and overruns the edge of the crucible during the early stages of the pyrolysis. In addition, when GR-S latex is ashed according to the procedure used for natural rubber latex, the carbonaceous residue formed on distillation may be removed only at temperatures that cause appreciable loss of inorganic material. Accordingly, techniques were developed for safely introducing either undried latex or rubber into the furnace at the ashing temperature, and for facilitating through the use of a washing treatment, the removal of the carbonaceous material formed in ashing GR-S latex. These techniques have been adopted for use in the official methods of the Government synthetic rubber program $[10,12,13]$, and should be applicable to other organic materials that may give rise to difficulties in ashing.

\section{Procedure}

GR-S. The sample to be tested is mill-massed on a laboratory rubber mill and sheeted. A 2- to 5-g

\footnotetext{
I Figures in brackets indicate the literature references at the end of this paper.
}

specimen of the sheeted rubber is weighed to the nearest milligram and wrapped in a single sheet of 15 -cm "ashless" filter paper by spreading it along a chord of the circle midway between the center and the edge. The paper is rolled into a tight cylinder around the rubber, and the ends of the filter paper are folded over the sample. The resulting roll is then folded over once or twice on itself and placed in a porcelain or aluminum crucible that has a volume of from 30 to $60 \mathrm{ml}$, and that has been ignited to constant weight $( \pm 0.2 \mathrm{mg})$ at $550^{\circ} \mathrm{C}$ plus or minus $25^{\circ} \mathrm{C}$. The crucible containing the wrapped specimen is placed directly into a muffle furnace maintained at $550^{\circ} \mathrm{C}$. plus or minus $25^{\circ} \mathrm{C}$. The door of the furnace is closed and should not be reopened until combustion of the carbonaceous material is nearly complete (30 to $60 \mathrm{~min}$.). After the carbon appears to have burned completely, the crucible is removed from the furnace, cooled to room temperature in a desiccator, and weighed. As a check for the complete removal of carbon, the specimen may be reheated for 30 -min. intervals until it has attained constant weight within $\pm 0.2 \mathrm{mg}$.

A correction should be made for the ash content of the filter paper when the effect is greater than 0.01 percent of the weight of the specimen.

GR-S Latex. A circle of ashless filter paper $9 \mathrm{~cm}$ in diameter is folded into the form of a cone, and inserted into a $60-\mathrm{ml}$ porcelain crucible previously ignited to constant weight $( \pm 0.2 \mathrm{mg})$ at $550^{\circ} \mathrm{C}$ plus or minus $25^{\circ} \mathrm{C}$. A small quantity of dry ashless filter pulp $(0.25$ to $0.50 \mathrm{~g})$ is pressed down into the bottom of the cone, and the crucible and its contents are weighed to the nearest milligram in a weighing bottle or friction top metal container. Five milliliters of latex, previously filtered through an 80-mesh stainless steel wire screen, are poured into the cone and the crucible, and its contents are reweighed to the nearest milligram. The crucible and its contents are placed directly into a muffle furnace maintained at $550^{\circ} \mathrm{C}$ plus or minus $25^{\circ} \mathrm{C}$. The door of the furnace is closed and should not be reopened for 45 to $60 \mathrm{~min}$. The crucible is then removed and allowed to cool until it may be touched by hand (about $10 \mathrm{~min}$.). Two to five drops of distilled water are added to the ash, the actual number depending upon the quantity of residue present. Sufficient time should be allowed between 
drops for the water to be absorbed by the residue before the next drop is added. An unabsorbed excess of water should be avoided, since it will cause spattering of the residue upon the side of the crucible during ashing, thus making subsequent washes more difficult. The dampened residue is ashed for one-half hour, and the alternate wetting and ashing procedures are repeated until all of the carbon appears to have been burned. The crucible and its contents are cooled to room temperature in a desiccator and weighed. As a check for the complete removal of carbon, the wetting and ashing techniques may be repeated again until the crucible and its contents have reached constant weight within $\pm 0.5 \mathrm{mg}$. This usually requires from two to five washes and a total time of 2 to 4 hours, depending upon the latex tested.

\section{Discussion of Techniques}

\subsection{Temperature of Ashing}

A temperature of $550^{\circ} \mathrm{C}$ was chosen to allow for the fairly rapid burning of both uncompounded GR-S and GR-S latex with a minimum loss of inorganic material through decomposition or volatilization. Reducing the temperature of the furnace below this point greatly slows down the rate of ashing. Lower temperatures are necessary only when the method is applied to certain compounded stocks containing appreciable quantities of materials that decompose or volatilize at this temperature [14]. The furnace door should be kept closed to prevent rapid burning and glowing of the specimen at temperatures that may be above the furnace temperature. Loss from explosion of the distilling gases during the early stages of the pyrolysis is prevented by the filter paper that appears to be intact at this time.

\subsection{Choice of Crucible}

Both aluminum ${ }^{2}[16]$ and porcelain crucibles have been found satisfactory for use in the determination of ash in GR-S. Aluminum crucibles are more suitable for rapid routine testing because they are (1) much less expensive; (2) more uniform in weight (approximately $5.2 \mathrm{~g}$ for those used in this work); (3) more rapidly cooled. The crucibles used in this work have straight sides and a relatively large base. Consequently, they are more stable and the wrapped specimen remains on the bottom of the crucible even when it tends to uncurl.

However, only porcelain crucibles may be used in ashing GR-S latices. Figure 1 shows the results obtained when both porcelain and aluminum crucibles are used. It was believed that the observed increase in the weight of the residue in the aluminum crucibles on repeated wetting and ashing resulted from a reaction between the aluminum and the water in the presence of the alkaline residue obtained

2 The aluminum crucibles used here were obtained on special order from The Aluminum Company of America in accordance with "drawing (Alcoa) F R $9747-\mathrm{X}$, capacity $35 / 16 \mathrm{cu}$. in., 28 gage material, $1^{35} 64 \mathrm{in}$. overall height,1.675 in. diameter, beveled at bottom., "The price at the time of purchase was approximately $\$ 14.00$ a thousand.

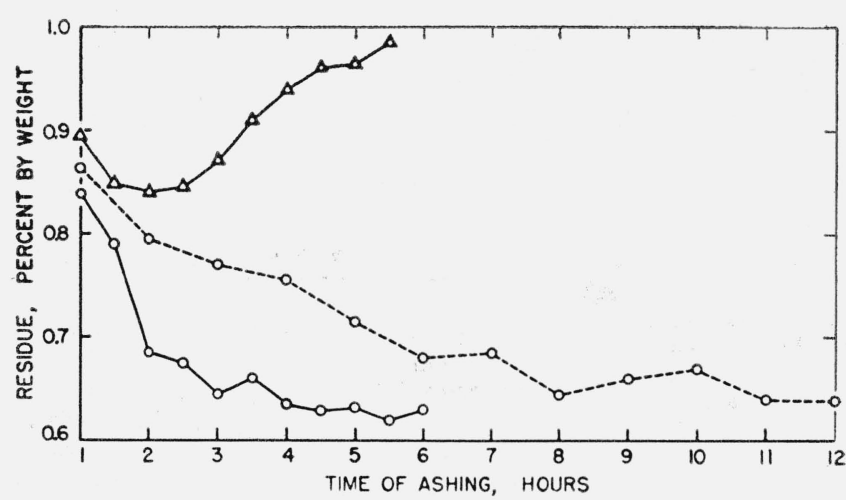

FIgURE 1. Effect of wetting residues of $G R-S$ latex and reheating for different periods of time in porcelain and aluminum crucibles.

$\bigcirc$, Porcelain crucibles; $\Delta$, aluminum crucibles; __. one-half-hour periods; -.., 1-hour periods.

from ashing the soap in the latex. Tests made by wetting pure sodium carbonate with water and heating as directed in the procedure lend support to this view.

\subsection{Use of Filter Paper and Pulp}

In addition to preventing loss from explosion the use of filter paper allows all types of GR-S polymers to be ashed without loss from frothing when introduced into the furnace at the ashing temperature. This technique has been used in ashing volatile metallo-organic compounds [11]. Oxalic acid or ammonium oxalate placed over the specimen in the crucible help to prevent "boiling over" of the polymer, but are not as satisfactory as filter paper. Rubber charred with nitric acid or treated with sulfuric acid or ammonium sulfate prior to ashing does not effervesce, but the resulting values are different from those obtained by the slow-ashing procedures [4, 8]. In addition, the ash obtained when the specimen is wrapped in filter paper is quite porous and fluffy, and can be readily extracted or dissolved for further analysis.

GR-S latex may be ashed without previously drying the specimen if ashless filter pulp is used to absorb the liquid and to prevent the spattering that would otherwise occur during the first few minutes in the furnace. Not only is a fluffy residue obtained, but the cone prevents the residue from adhering to the walls of the crucible. The washing and burning of the carbonaceous material are thus facilitated.

\subsection{Washing of the Ash}

It is believed that the slow and incomplete ashing of GR-S latex is due to a protective layer of salt that covers the carbon formed when the polymeric portion of the latex is burned. It is probable that treating the residue with small portions of water removes at least part of this coating of salt, permitting an additional portion of the carbon to be burned. Qualitative tests indicate the presence of carbonate resulting from ashing the soap present in the original latex. Since the coagulated polymer contains but 
little soap, GR-S may be ashed within 1 hour without the washing treatment. Nitric acid, sulfuric acid, hydrochloric acid, and aqueous solutions of oxalic acid have been used to wash the residue. Only one treatment with any of the mineral acids is required to yield a carbon-free ash, but since these acids alter the composition of the ash, the resulting values though reproducible are different from those obtained when no treatment is used. Since oxalic acid offered no advantage over water, water was chosen. This technique of wetting the carbonaceous residues with water to facilitate burning is simpler than a number of previous methods $[1,5,6]$.

Figure 1 shows the effect of using two different periods of heating between water washes. Apparently, the use of one-half-hour heating periods reduces the time required for ashing by 50 percent. Further reduction of the heating periods is not helpful.

\section{Results}

In order to determine the over-all precision of the tests when used over an extended period, duplicate determinations were made daily for 5 to 10 days on samples of GR-S and GR-S latex. The particular samples of GR-S used were chosen because of their marked tendency to overrun the edge of the crucible when rapidly ashed without the use of filter paper. The samples of GR-S latex used were chosen because they characterize differences in latex types that might effect either the final results or the ease of testing. Both porcelain and aluminum crucibles were used in testing the GR-S rubber samples so that the values obtained might be compared. For further comparison the same rubber samples were tested according to the slow-ashing process $[4,8]$ without previous extraction.

The results of these tests are given in tables 1 and 2. An analysis of variance [15] made of the data

TABLE 1. Ash content of $G R-S$ synthetic rubber samples

\begin{tabular}{|c|c|c|c|c|c|c|c|}
\hline \multirow{2}{*}{\multicolumn{2}{|c|}{ Procedure }} & \multicolumn{2}{|c|}{$\mathrm{X}-243 \mathrm{AC}^{\mathrm{a}}$} & \multicolumn{2}{|c|}{$\mathrm{X}-346 \mathrm{AC}^{\mathrm{a}}$} & \multicolumn{2}{|c|}{$\mathrm{X}-452 \mathrm{AC}^{\mathrm{a}}$} \\
\hline & & $\begin{array}{l}\text { Porce- } \\
\text { lain } \\
\text { cruci- } \\
\text { bles }\end{array}$ & $\begin{array}{c}\text { Alumi- } \\
\text { num } \\
\text { cruci- } \\
\text { bles }\end{array}$ & $\begin{array}{l}\text { Porce- } \\
\text { lain } \\
\text { cruci- } \\
\text { bles }\end{array}$ & $\begin{array}{l}\text { Alumi- } \\
\text { num } \\
\text { cruci- } \\
\text { bles }\end{array}$ & $\begin{array}{l}\text { Porce- } \\
\text { lain } \\
\text { cruci- } \\
\text { bles }\end{array}$ & $\begin{array}{l}\text { Alumi- } \\
\text { num } \\
\text { cruci- } \\
\text { bles }\end{array}$ \\
\hline \multirow[t]{2}{*}{ Present $\left\{\begin{array}{l}\mathrm{I} \\
s,\end{array}\right.$} & $\begin{array}{l}\text { Mean } \\
\text { Ligh } \\
\text { Low }\end{array}$ & $\begin{array}{l}\text { Per- } \\
\text { cent } \\
0.778 \\
.83 \\
.74 \\
.023\end{array}$ & \begin{tabular}{|} 
Per- \\
cent \\
0.770 \\
.80 \\
.72 \\
.022
\end{tabular} & $\begin{array}{l}\text { Per- } \\
\text { cent } \\
0.536 \\
.55 \\
.50 \\
.016\end{array}$ & $\begin{array}{c}\text { Per- } \\
\text { cent } \\
0.545 \\
.58 \\
.52 \\
.018\end{array}$ & $\begin{array}{c}\text { Per- } \\
\text { cent } \\
0.496 \\
.56 \\
.45 \\
.029\end{array}$ & $\begin{array}{c}\text { Per- } \\
\text { cent } \\
0.502 \\
.54 \\
.46 \\
.022\end{array}$ \\
\hline & $\begin{array}{l}\text { to. } \\
\text { tions }\end{array}$ & 10 & 10 & 10 & 10 & 20 & 20 \\
\hline \multirow{4}{*}{ Slow-ashing } & 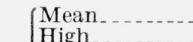 & 0.749 & ... & 0. 504 & ... & 0.509 & -.. \\
\hline & Lo & .72 & ... & $\begin{array}{l}.50 \\
.46\end{array}$ & $\cdots$ & $\begin{array}{l}.00 \\
.47\end{array}$ & $\cdots$ \\
\hline & $\mid \begin{array}{l}s_{r} \mathrm{~b} \\
\text { No. of deter- }\end{array}$ & (c) & & (c) & 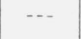 & .026 & -.. \\
\hline & minatio & 20 & -.. & 16 & -.. & 30 & -.. \\
\hline
\end{tabular}

a These designations apply to samples of alum-coagulated GR-S used as reference lots in the control testing of this type of $\mathrm{GR}-\mathrm{S}$ production in the government synthetic rubber plants.

synthetic rubber plants. cluding both within-day and day-to-day variability.

These determinations were made over too short a period to permit a reliable estimate of $s_{r}$.
TABLE 2. Ash content of different types of $G R-S$ synthetic rubber latices a

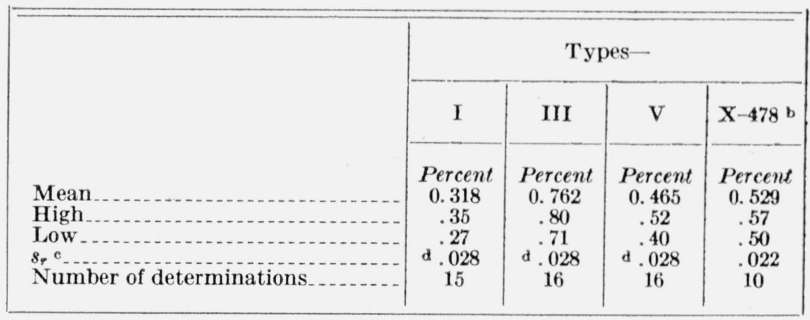

a The designations given are for different types of commercially available latices. Types I, III, and V were tested simultaneously.

b GR-S latex polymerized at $41^{\circ} \mathrm{F}$.

c $s_{r}$ represents the standard deviation of a single random determination ineluding both within-day and day-to-day-variability.

$d$ This value of $s_{r}$ was calculated from the pooled data obtained with the three ty pes of latex tested simultaneously.

showed a significant, but small, day-to-day variability for the tests used on both the rubber and latex. This variability was not sufficiently large to affect appreciably the values for the over-all precision, $s_{r}$, that is, the standard deviation of a single random determination given in the tables. The values of $s_{r}$ for each of the tests are of the same order of magnitude as that obtained when GR-S is analyzed by the older slow-ashing process. In addition, the data obtained for GR-S rubber indicate at least as good retention of material by the new process as by the old. A similar comparison for GR-S latex cannot be made, since the older slow-ashing methods are not applicable to this material. Though the ash is not necessarily identical with the inorganic material originally present in the sample, because of the decomposition of soaps, etc., the residue represents the original adequately for specification purposes.

\section{References}

[1] Am. Soc. Testing Materials, ASTM 1949 Standards, Part 5, Designation D 128-47, p. 758.

[2] Am. Soc. Testing Materials, ASTM 1949 Standards, Part 5, Designation D 377-47T, p. 152.

[3] Am. Soc. Testing Materials, ASTM 1949 Standards, Part 5, Designation D 584-47, p. 380.

[4] Am. Soc. Testing Materials, ASTM 1949 Standards, Part 6, Designation D 297-43T, p. 816.

[5] Association of Official Agricultural Chemists, Official and Tentative Methods of Analysis of the Association of Official Agricultural Chemists, Designation 6.107, p. 73 (1945).

[6] Association of Official Agriciltural Chemists, Official and Tentative Methods of Analysis of the Association of Official Agricultural Chemists, Designation 10.5, p. 107 (1945).

[7] British Standards Institution, British standard methods of testing latex, raw rubber, and unvulcanized compounded rubber, Bull. BS 902, p. 9 (June 1940).

[8] British Standards Institution, British standard methods of testing latex, raw rubber, and unvulcanizied compounded rubber, Bull. BS 902, p. 20 (June 1940).

[9] British Standards Institution, British Standard methods of testing vulcanized rubber, Bull. BS 903, p. 55 (Oct. 1950)

[10] R. I. Cohen, L. T. Milliken, and F. J. Linnig, The determination of ash in GR-S latices, unpublished report to Office of Rubber Reserve (May 8, 1950).

[11] W. F. Hillebrand and G. E. F. Lundell, Applied inorganic analysis, p. 317, 1st ed. (John Wiley and Sons, Inc., New York, N. Y., 1929). 
[12] L. T. Milliken, The use of aluminum crucibles for the determination of ash in $\mathrm{GR}-\mathrm{S}$, unpublished report to Office of Rubber Reserve (July 24, 1947).

[13] L. T. Milliken and F. J. Linnig, Determination of ash in alum-coagulated GR-S, unpublished Report to Office of Rubber Reserve (Feb. 21, 1949).

[14] J. R. Scott, J. Rubber Research 14, 150 (1945).

[15] G. W. Snedecor, Statistical methods, 4th ed. (The Collegiate Press, Ames, Iowa, 1946).
[16] J. R. Todd, Government Evaluation Laboratories, Akron, Ohio, Private communication (March 12, 1946).

[17] U. S. Rubber Co., Agent, Office of Rubber Reserve, Institute, West Virginia, private communication (April 25, 1944).

[18] G. H. Vila, Vanderbilt rubber handbook, 9th ed., p. 263 (R. T. Vanderbilt Co., New York, N. Y., 1948).

Washington, August 31, 1950. 